\title{
Flow analysis with WaSiM-ETH - model parameter sensitivity at different scales
}

\author{
J. Cullmann, V. Mishra, and R. Peters \\ Institute of Hydrology and Meteorology, University of Technology, Dresden, Germany \\ Received: 23 January 2006 - Revised: 22 May 2006 - Accepted: 3 July 2006 - Published: 26 September 2006
}

\begin{abstract}
WaSiM-ETH (Gurtz et al., 2001), a widely used water balance simulation model, is tested for its suitability to serve for flow analysis in the context of rainfall runoff modelling and flood forecasting. In this paper, special focus is on the resolution of the process domain in space as well as in time. We try to couple model runs with different calculation time steps in order to reduce the effort arising from calculating the whole flow hydrograph at the hourly time step. We aim at modelling on the daily time step for water balance purposes, switching to the hourly time step whenever high-resolution information is necessary (flood forecasting). WaSiM-ETH is used at different grid resolutions, thus we try to become clear about being able to transfer the model in spatial resolution. We further use two different approaches for the overland flow time calculation within the sub-basins of the test watershed to gain insights about the process dynamics portrayed by the model. Our findings indicate that the model is very sensitive to time and space resolution and cannot be transferred across scales without recalibration.
\end{abstract}

\section{Introduction}

Identifying the dominant process controls at different scales is the starting point of any discussion of scaling issues in hydrology. Beven (2001) described the problem of scaling as the difficulty to apply a hydrological model to a particular catchment with its own, unique characteristics. As a last consequence of this view, scaling theories will ultimately prove to be impossible (Beven, 2001). It is therefore necessary to accept the scale dependence of model structures. Contrary to this belief, Blöschl (2001) suggests that resolving the scaling problem is possible. Real advances in hydrological practice and theorising will arise from the solution of the scaling

Correspondence to: J. Cullmann

(johannes.cullmann@mailbox.tu-dresden.de) dilemma. However, hydrological systems are described by non-linear functions, taking into account antecedent conditions as well as rainfall volume and rainfall distribution for the surface and subsurface processes of runoff generation. This leads us to non-linear models, where the scaling process might become difficult, especially with rising numbers of effective parameters.

Portraying the complexity of hydrological processes in a model is a well-known sore point to the hydrological community. Including more complexity into models possibly leads to more reliable results as far as stream flow simulation is concerned. This is not always the case, as Butts et al. (2004) describe results of investigations in the Blue River Basin in Oklahoma where sensitivity due to the variation of acceptable model structures are of the same magnitude as the uncertainties arising from other sources (discharge measurement, parametric uncertainty, rainfall measurement). This suggests that there can be important benefits in exploring different model structures as part of the modelling approach.

In this context, within the broader frame of the general behaviour of the WaSiM-ETH model, we focus on the soil module, the latter representing the crucial part of the WaSiM-ETH runoff generation and concentration approach. In Sects. 2 and 3 of this paper we shortly introduce the model and study area respectively. After the preliminary sensitivity analysis described in Sect. 4.1 we use the model at different resolutions (time and space) in order to learn about the specific model behaviour in scaling issues (Sects. 4.2 and 4.3).

To evaluate the impact of different underlying structures we exemplarily investigate on the degree of complexity of the flow time determination (Sect. 4.4). This leads to differing results depending on the dominant processes of the considered event. 


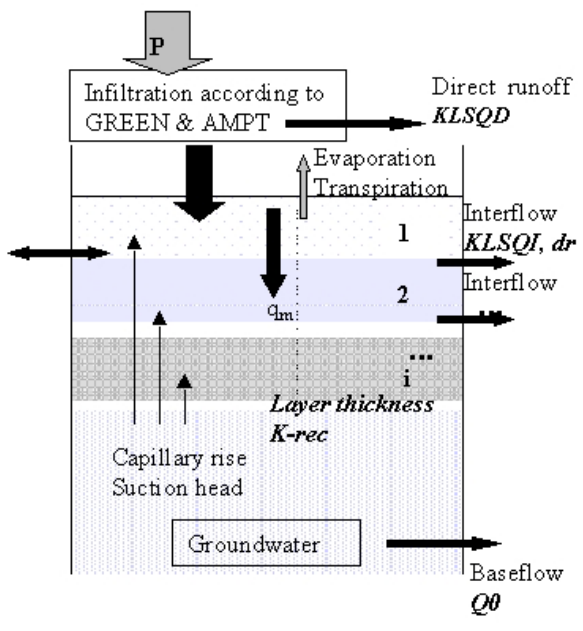

\begin{tabular}{|c|c|c|}
\hline$K L S Q D$ & Recession constant for direct runoff & Runoff concentration \\
\hline$K L S Q I$ & Recession constant for interflow & Runoff concentration \\
\hline$d r$ & Drainage parameter & Runoff generation \\
\hline$K-$ rec & $\begin{array}{c}\text { Factor controlling decrease of } \\
\text { hydraulic conductivity with soil depth }\end{array}$ & Runoff generation \\
\hline$Q 0$ & Scaling factor for base flow & Runoff generation \\
\hline $\begin{array}{c}\text { Layer } \\
\text { thickness }\end{array}$ & Soil discretisation & Computation set up \\
\hline
\end{tabular}

Fig. 1. Soil water module structure of WaSiM-ETH (investigated parameters are marked in bold), $P$ denotes precipitation, $q m$ is the soil compartment flow.

\section{The model}

WaSiM-ETH is a modular system. It comprises the interpolation of meteorological input data. Various modules then describe interception, snow accumulation and snowmelt as well as evapotranspiration. Radiation correction for different slopes and aspects is optional as well as a rainfall correction. With the aid of the Green-Ampt approach the direct runoff is determined and a stable boundary condition is provided for modelling soil water dynamics with the 1D-Richards equation. The soil discretisation into i layers allows for the calculation of interflow from each layer. A detailed scheme of the soil module, together with the investigated parameters, is given in Fig. 1. Groundwater dynamics is portrayed by a 2D module or with an optional lumped conceptual approach. In our study we used the latter option because reliable information on aquifers in the mountainous catchment is not available. WaSiM-ETH routs the channel flow by means of a translation module with a simple storage built in to account for diffusion. For a more detailed model description we refer to Schulla and Jasper (1999).
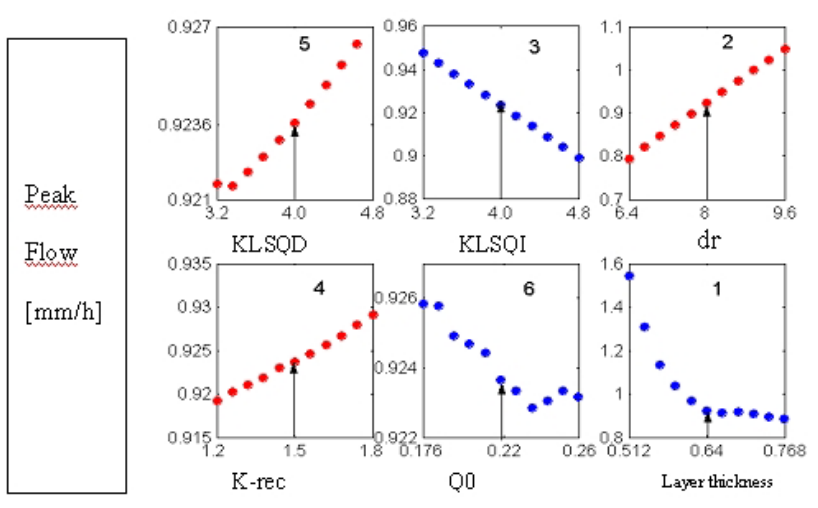

Fig. 2. Ranked sensitivity for soil parameters in WaSiM-ETH. Arrows mark best fit for the calibrated event.

\section{Study area and data}

The study area is a $117 \mathrm{~km}^{2}$ subcatchment of the Schwarze Pockau River. The nearest gauging station represents $129 \mathrm{~km}^{2}$ and is situated a few 100 meters downstream of the watershed outlet used in our study. The watershed under consideration covers the northern slopes of the Ore Mountains in Eastern Germany from about $900 \mathrm{~m}$ a.m.s.l. down to $300 \mathrm{~m}$ a.m.s.l. Roughly $40 \%$ of the watershed is covered by forest whilst the agriculturally used area accounts for about $30 \%$, the rest being fallow land or characterized by human settlements. The basin hydrology is near natural state; there are no major human impacts on the flow dynamics. We use the soil map Bük 200 (scale 1:200000) for soil classification and derive the Van Genuchten parameters according to the AG Boden (2005), this results in an effective parameter set characterizing the soil, which might not sufficiently represent the true parameter distribution within our test site. But as we focus on the general behaviour of WaSiM-ETH and no more detailed data is easily available no further effort was made to support or correct our parameters (i.e. with field investigations). The land use data was taken from Corine (2000). The meteorological data used in the study consisted of $1 \mathrm{~km}$ grids of precipitation, temperature, wind speed, air humidity and global radiation of the years 1974, 1983 and 2002. The data was interpolated from station data using external drift kriging for precipitation and temperature and ordinary kriging for the other input data.

\section{Investigations on the model behaviour}

\subsection{Simple sensitivity analysis}

In our study we used a simple sensitivity analysis, focusing on the parameters of the soil model. Amongst others, we use the soil layer thickness in this first analysis, although it is a numerical parameter used to discretisize the solution of the Richards-Equation. The soil layer thickness therefore 


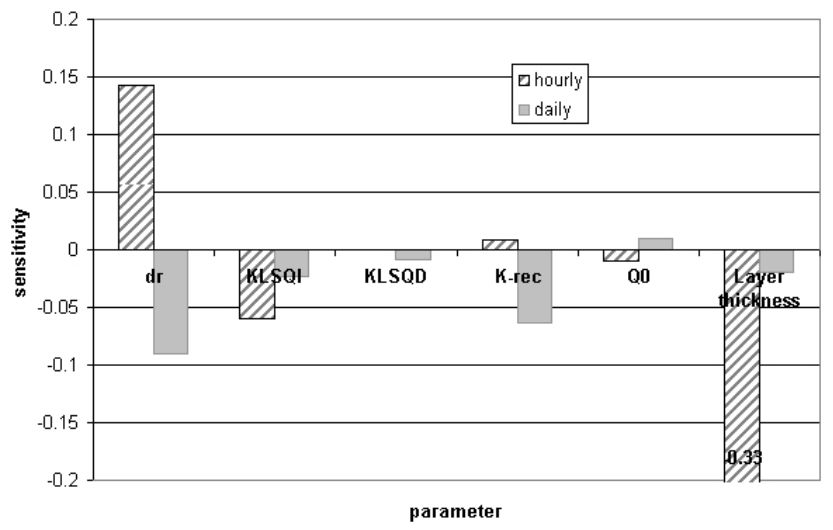

Fig. 3. Sensitivity measure (Eq. 3) for different modelling time steps.

depends on the space-time set up of the model domain, and must not be considered as a process parameter. To control the overall soil thickness the number of soil layers can be adjusted. Nevertheless, in WaSiM-ETH, this parameter has effect on the runoff generation and the setting should be exercised with caution. Interflow is calculated in a two-step approach in WaSiM-ETH. At first, a maximum possible interflow $\left(q_{\mathrm{ifl}, \max }\right)$ is calculated by means of Eq. (1).

$q_{\text {ifl, } \max }=\left(\Theta(\psi)=\Theta_{\psi=3.45}\right) \cdot \Delta z \cdot \Delta t$

With $\Theta(\psi)$ water content at actual suction $\psi[-]$

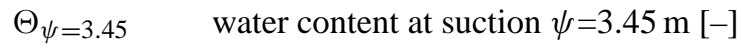

$\Delta z \quad$ layer thickness [m]

$\Delta t \quad$ time step [s].

In a second step, a conceptual interflow rate is calculated according to Eq. (2).

$q_{\text {ifl }}=k_{s}\left(\Theta_{m}\right) \cdot \Delta z \cdot d_{r} \cdot \tan \beta$

where $k_{s} \quad$ saturated hydraulic conductivity $[\mathrm{m} / \mathrm{s}]$

$\Theta_{m} \quad$ water content of layer $m[-]$

$\Delta z \quad$ soil layer thickness [m] $d_{r}$ drainage parameter $\beta \quad$ slope.

Eqautions (1) and (2) are both calculated, the smaller result is then taken as the interflow rate.

Figure 2 shows the results of the simple sensitivity analysis. Only one parameter at a time was varied (uniform distribution, 5\% parameter value changes per step). The sensitivity analysis was carried out with respect to the peak flow. We can easily see, that the layer thickness is the most sensitive parameter for the soil water dynamics, closely followed by the drainage $\left(d_{r}\right)$ parameter. While $\mathrm{dr}$ is a simple scalar the soil layer thickness shows a non-linear behaviour. For model calibration $d_{r}$ is the more suitable parameter, soil layer thickness should once be set according to the results obtained from close examination of numerical stability criteria.

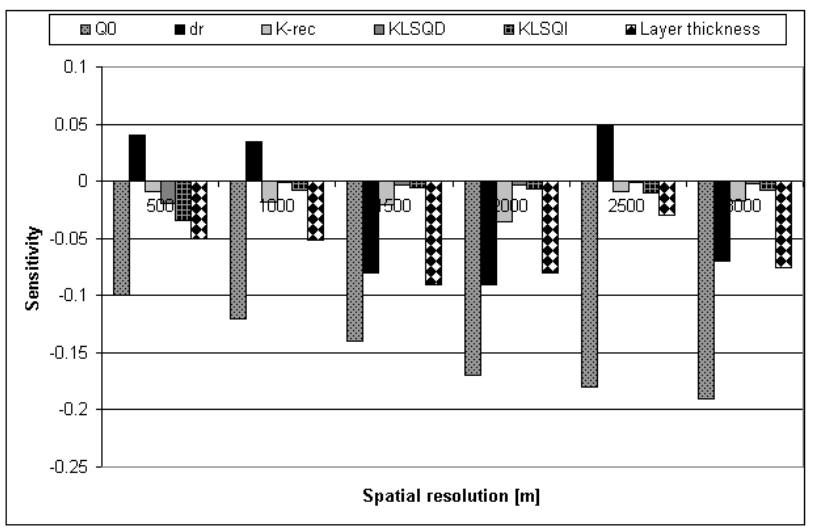

Fig. 4. Sensitivity measure $S$ (Eq. 3) for selected model parameters on different grid resolutions.

\subsection{Varying modelling time steps}

The model was used at the daily time step to calculate the water balance up to a date of interest. Then the time step was switched to hours in order to refine the information in the time frame of interest (flood event). A simple sensitivity measure (Eq. 3) was calculated in order to check upon the feasibility of this approach.

$S=\frac{(P(+10 \%)-P(-10 \%))}{P}$

With $S$ sensitivity measure [-]

$P_{+10 \%} \quad$ peak discharge of the considered flow hydrograph

for parameter $+10 \%$

$P_{-10 \%}$ peak discharge of the considered flow hydrograph for parameter $-10 \%$

$P \quad$ peak discharge of the considered flow hydrograph for standard parameter set.

Figure 3 clearly shows, that the most sensitive parameters in the soil model, i.e. the main parameters influencing the processes of runoff generation, show differing sensitivity to parameter variation on different levels of time resolution. This makes recalibration necessary if the time step is switched. The modelling time step cannot be simply switched from hourly to daily and vice versa.

\subsection{Varying modelling resolution in space}

WaSiM-ETH has been used for seven grid resolutions varying from $500 \mathrm{~m}$ to $3500 \mathrm{~m}$ in our test watershed. The land use and soil type data were therefore up-scaled from the original $500 \mathrm{~m}$ grids by means of the standard nearest neighbour approach implemented in GRASS-GIS. The evaluation criterion for this study is the simple sensitivity index according to Eq. (3). The somewhat discouraging result of this exercise is shown in Fig. 4. It is far from any kind of functional relationship that would allow for the allocation of parameters 


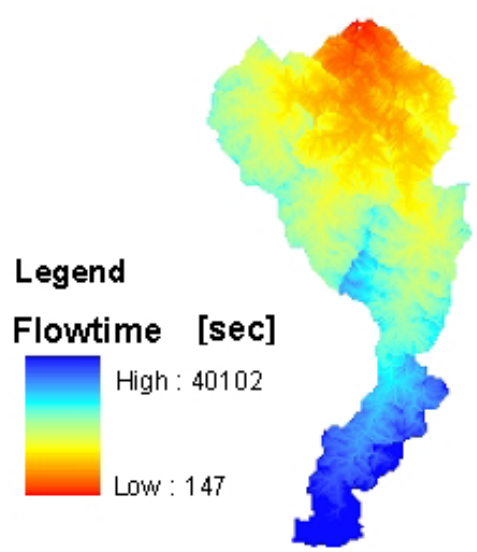

Flowtime

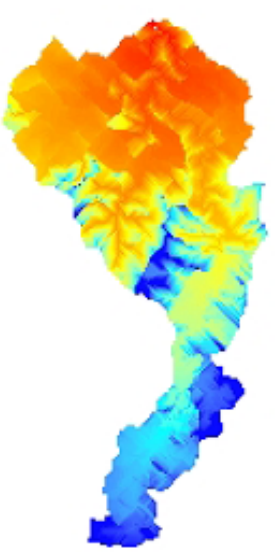

Flowtime

\section{topography landuse}
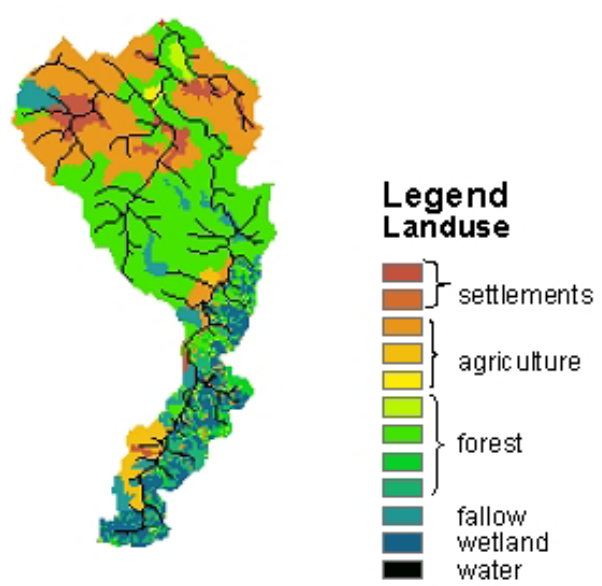

\section{landuse}

Fig. 5. Flow times of two different modeling approaches (TANALYSIS; empirical functions according to Dyck (1983)) as well as the land use distribution in at the test site.

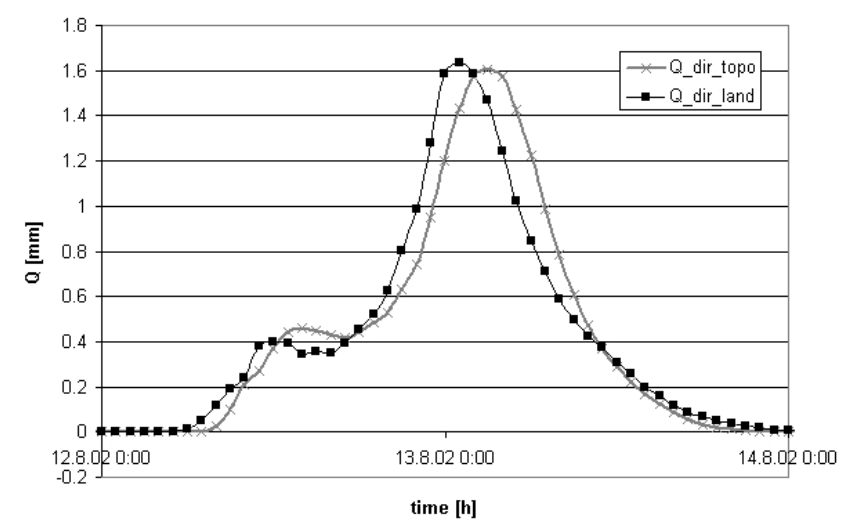

Fig. 6. Direct runoff components for the summer flood event 2002. Q_dir_topo is the topology based flow time, Q_dir_land is the combined landuse and topology based flow.

at different grid sizes, especially if various parameters are involved in the calibration process. There is no trend that could encourage formulating a rule-based system for the parameter handling at different grid scales. Especially the scalar $\mathrm{dr}$ is highly unstable if the sensitivity value is considered. Some of this sensitivity might be explained with the different soil type proportions on differing resolutions, which are not accounted for by the sensitivity measure. Based on our study alone we are not able to find any precise rules on space dependant parameter sensitivity. It would be useful to repeat this study with artificial data and uniform soil and land use data.

\subsection{Process representation in modelling}

A test has been carried out in order to deepen our knowledge about the impact of different representations of a certain process in the given modelling framework. We have therefore used two different approaches to calculate the overland flow time for the sub-basins of our watershed. The flow time is used in the runoff concentration of WaSiM-ETH. The first method we employed is the standard method used in TANALYSIS (Schulla and Jasper, 1999). Here, the flow time is a function of the slope alone. The second test method is based on the assumption that overland flow velocities in watersheds do not depend on the slope alone, but also on the land cover. Therefore we have set up a GRASS-tool (Dröge, 2004) which implements the empirical functions of Dyck (1983), who published flow times for the study area as a function of the slope and land use. The differences in flow times can be seen in Fig. 5. The agricultural areas in the lower parts of the watershed have an accelerating effect on overland flow, while the forested parts of the upper basin show a more gradual response compared to the flow times calculated by means of the slope alone. A test run for the summer 2002 flood event is shown in Fig. 6. As expected from the flow time distribution the variant which is based on slope and land use shows a faster reaction due to lower flow times in the agriculturally used reaches. The beginning of direct runoff starts $2 \mathrm{~h}$ earlier than in the model version with the purely slope based flow time. The main peak is somewhat lower, because a significant part of the flow has left the watershed before the water from the forested upland reaches the lower parts of the watershed. The peak flow occurs two hours earlier for the land use based approach. For a watershed with a travel time 
of about six hours this seems to be a substantial difference in flow dynamics. As we do not have any validation data for overland flow we are not able to discriminate between these two approaches.

\section{Conclusions}

WaSiM-ETH (in the version 2 with 1D-Richards equation) is a model well suited for water balance simulations (Gurtz et al., 2000). If used in an event based modelling context with the intention to analyze total runoff or runoff components, the model is to be used with care. A drawback is the spatial and temporal dependency of the model parameters. If the temporal scale is varied, the model needs to be recalibrated for the different scales. This makes temporally high resolute applications of WaSiM-ETH slow for long time series, as the iterative solution of the 1D-Richards equation requires considerable numerical effort. Another result of the studies presented in this paper is the pronounced sensitivity of WaSiM-ETH to model parameters for different spatial discretisations. This could partly be due to variable shares of soil and land use type for different grid sizes. For a final evaluation of this phenomenon the study has to be repeated with simplified artificial soil and land use maps in order to avoid the aforementioned distortion of the results.

The process representation exemplarily tested in Sect. 4.4 of this paper reveals that WaSiM-ETH is quite sensitive to the different approaches used for overland flow time determination. This underlines the statement that the model should be used with extreme care as a more or less realistic representation of the flow time leads to different parametrerizations when the model is calibrated against a measured flow. In the presented example a major flood was used to investigate the direct runoff. If the model is used for flood events with differing direct runoff/interflow shares the results might be different. This also has to be seen in the light of the specific land use distribution within the test catchment with the forested area in the upper catchment farther away from the catchment outlet. The impact of the shown effect can be larger or smaller with different land use and land use distribution. Therefore this study only spotlights some of the problems encountered when using WaSiM-ETH for flow analysis. We thus can only encourage the hydrologic community to further investigate on the impact of model resolution and model process representation on the results of rainfall-runoff models. A thorough comparison of different models under the aforementioned aspects would also help researches to judge future model parameterizations and results.
Edited by: R. Barthel, J. Götzinger, G. Hartmann, J. Jagelke, V. Rojanschi, and J. Wolf

Reviewed by: anonymous referees

\section{References}

AG Boden: Pedological Mapping Instructions, Federal Institute of Geosciences and Resources, Schweizerbartsche Verlagsbuchhandlung, 2005.

Beven, K.: How far can we go in distributed hydrological modelling?, Hydrol. Earth Syst. Sci., 5(1), 1-12, 2001.

Blöschl, G.: Scaling in hydrology, Hydrol. Process. (HPToday), 15, 709-711, 2001.

Butts, M. B., Payne, J. T., Kristensen, M., and Madsen, H.: An evaluation of the impact of model structure on hydrological modelling uncertainty for streamflow simulation, J. Hydrol., 298, 242-266, 2004.

Dröge, W.: Flow time calculation with respect to landuse, Institute of Hydrology \& Meteorology, TU-Dresden, 1-4, 2004.

Dyck, S.: Grundlagen der Hydrologie (Principles of Hydrology), VEB Bauwesen, Berlin, 1983.

Gurtz, J., Zappa, M., Jasper, K., Lang, H., Badoux, A., Verbunt, M., and Vitvar, T.: Modelling and validation of runoff and its components in Swiss Pre-Alpine and Alpine catchments, International Workshop on runoff generation and implications for river basin modelling, Freiburg i.Br., 9-12 October 2000, Freiburger Schriften zur Hydrologie, 13, 2001.

Schulla, J. and Jasper, K.: Model description WaSiM-ETH, ETH, Zürich, 1999. 